\title{
Cyclical Combination Chemotherapy for Advanced Breast Carcinoma
}

\author{
GEORGE P. CANELLOS, VINCENT T. DEVITA, \\ PHILIP S. SCHEIN, ROBERT C. YOUNG
}

British Medical fournal, 1974, 1, 218-220

\begin{abstract}
Summary
Twenty-five patients with advanced metastatic breast cancer were treated with the combination of methotrexate $60 \mathrm{mg} / \mathrm{M}^{2}$ and 5-fluorouracil $700 \mathrm{mg} / \mathrm{M}^{2}$ intravenously on the first and eighth days, and cyclophosphamide $100 \mathrm{mg} / \mathrm{M}^{2}$ and prednisone $40 \mathrm{mg} / \mathrm{M}^{2}$ by mouth daily for the first 14 days of a 28 -day cycle. The patients had had no previous chemotherapy or extensive radiotherapy and all but two had not responded to hormonal therapy or endocrine ablation. The major metastatic lesions were: lung (12 patients), liver (four patients), bone (four patients), soft tissue (three patients), nodes (two patients). Seventeen of the 25 patients $\left(68^{\circ}{ }_{0}\right)$ responded to treatment with seven complete remissions; these included patients suffering metastatic lesions in the lung, nodes, and soft tissue. The overall median duration of response was nine months (range 6-26 months). Toxicity was primarily haematological, but the group received an average of at least $\mathbf{7 5} \%$ of their calculated dose for each monthly cycle. Haematological toxicity was most pronounced in patients with liver dysfunction and bone marrow involvement. Out of eight nonresponders seven died, with a median survival of six months. Only six of 17 responders died, and the median survival in this group will exceed thirteen months. There was no correlation between the length of the metastasis-free interval after previous treatment and subsequent response to chemotherapy.
\end{abstract}

\section{Introduction}

A variety of cytotoxic chemotherapeutic agents with differing mechanisms of action have been useful in the treatment of advanced breast cancer. They have generally been given as single agents and have been associated with partial tumour regressions in about $10-30 \%$ of patients (Ansfield et al., 1969; Eastern Co-operative Group in Solid Tumour Chemotherapy, 1967; Fracchia, et al., 1970; Nemoto and Dao, 1971; Sears et al., 1966). Previous investigations in acute leukaemia and Hodgkin's disease have shown that combinations of effective agents can improve the complete remission rate and increase the survival rate over that previously achieved with single drugs (DeVita and Schein, 1973). We here report on the results of a National Cancer Institute study of cyclical combination chemotherapy for advanced breast cancer.

\footnotetext{
Medicine Branch, National Cancer Institute, Bethesda, Maryland 20014, U.S.A.

GEORGE P. CANELLOS M.D., Assistant Chief of the Medicine Branch VINCENT T. DEVITA, M.D., Chief of the Medicine Branch

G. LENNARD GOLD, M.D., Visiting Physician

BRUCE A CHABNER, M.D, Senior Investigator

PRULE A. CHABNER, M.D., Senior Investigator

ROBERT C. YOUNG, M.D., Senior Investigator
}

\author{
G. LENNARD GOLD, BRUCE A. CHABNER,
}

\section{Patients and Methods}

Twenty-five women with advanced breast cancer were treated with a regimen which included the intravenous administration of methotrexate $60 \mathrm{mg} / \mathrm{M}^{2}$ and 5 -fluorouracil $700 \mathrm{mg} / \mathrm{m}^{2}$ on the first and eighth days of a 28 -day cycle with the concomitant oral administration of cyclophosphamide $100 \mathrm{mg} / \mathrm{M}^{2}$ and prednisone $40 \mathrm{mg} / \mathrm{M}^{2}$ daily for 14 days (table I). The patient was then left 14 days off all treatment and a new cycle was begun every 28 days. The doses were decreased according to prescribed scale if the heamatological values had not returned to normal. To be eligible for study the patients had to have had no previous chemotherapy, no previous extensive spinal or pelvic radiation, a life expectancy of over two months, and, ideally, measurable visceral or soft tissue disease or both. The protocol entailed the administration of at least six monthly cycles. Patients who achieved a complete remission were given four subsequent cycles. Patients whose disease continued to respond but not completely were given combination chemotherapy until there was evidence of refractoriness.

TABLE I-Single Cycle of Combination Chemotherapy $(+=$ Drugs Given $)$

\begin{tabular}{|c|c|c|c|c|c|c|c|c|c|c|c|c|c|c|c|}
\hline \multirow{2}{*}{ Drugs } & \multicolumn{15}{|c|}{ Day } \\
\hline & 1 & 2 & 3 & 4 & 5 & 6 & 7 & 8 & 9 & 10 & 11 & 12 & 13 & 14 & 28 \\
\hline $\begin{array}{l}\text { I.V. Methotrexate } \\
\left(60 \mathrm{mg} / \mathrm{m}^{2}\right) \\
\text { I. } 6.5-\mathrm{Flourourail} \\
\left(700 \mathrm{mg} / \mathrm{m}^{2}\right) \\
\text { Oral Cyclophosphamide } \\
\quad\left(100 \mathrm{mg} / \mathrm{m}^{2} / \text { day) }\right. \\
\text { Oral Prednisone } \\
\quad\left(40 \mathrm{mg} / \mathrm{m}^{2} / \text { day) }\right.\end{array}$ & $\begin{array}{l}+ \\
+ \\
+ \\
+\end{array}$ & $\begin{array}{l}+ \\
+\end{array}$ & $\begin{array}{l}+ \\
+\end{array}$ & $\begin{array}{l}+ \\
+\end{array}$ & $\begin{array}{l}+ \\
+\end{array}$ & $\begin{array}{l}+ \\
+\end{array}$ & $\begin{array}{l}+ \\
+\end{array}$ & $\begin{array}{l}+ \\
+ \\
+ \\
+\end{array}$ & $\begin{array}{l}+ \\
+\end{array}$ & $\begin{array}{l}+ \\
+\end{array}$ & $\begin{array}{l}+ \\
+\end{array}$ & $\begin{array}{l}+ \\
+\end{array}$ & $\begin{array}{l}+ \\
+\end{array}$ & $\begin{array}{l}+ \\
+\end{array}$ & \\
\hline
\end{tabular}

The responses were categorized as complete or partial regression of measurable disease. A complete response was defined as the complete resolution of all measurable disease. A partial antitumour response included at least $50 \%$ regression of measurable disease for over two months. Patients with multiple organ involvement in whom some lesions completely regressed but others did not change or partially regressed were classified as partial responders. Symptomatic involvement per se and regression of pleural effusions were not considered as objective responses. Responses of radiographically evident bone lesions are difficult to evaluate, and in this study only radiographic and biopsy evidence of tumour regression or bone healing or both were considered objective criteria.

The median age of the 25 patients was 47 (range 23-63). Seven were postmenopausal and 18 premenopausal. All but two had received some form of previous hormonal or endocrine ablative treatment. All 18 of the premenopausal patients had had an oophorectomy and one had also had an adrenalectomy. One patient had partially responded to oophorectomy. Five of the seven postmenopausal patients had received oestrogen therapy and one had responded transiently. Of the 25 patients 22 had had a radical mastectomy and 14 of these had positive axillary nodes. Sixteen of these patients had also received adjuvant radiation treatment, and two had received therapeutic radiation. The median disease-free period for the patients who had undergone mastectomy and radiation was 16 months (range 0-80 months). The median time from diagnosis of metastatic disease 
to chemotherapy was three months. Staging of metastatic disease was complex because of the variations of disease presentation; the distribution of metastatic sites is shown in table II. Pulmonary involvement was the major metastatic site in almost half the patients. Less prominent metastatic lesions are included under each major site. In three of the six cases of liver metastases the diagnosis was confirmed by biopsy, while gross clinical findings, positive liver scans, and chemical abnormalities were present in the others. Bone metastases predominated in four patients.

TABLE II-Dominant and Secondary Metastatic Lesions in 25 Patients before Chemotherapy

\begin{tabular}{|c|c|c|c|c|c|}
\hline \multirow{2}{*}{ Secondary Lesions } & \multicolumn{5}{|c|}{ Dominant Lesions } \\
\hline & Lung & Nodes & Soft Tissue & Liver & Bone \\
\hline 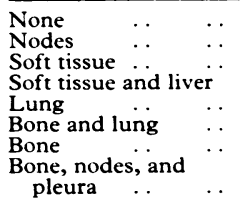 & $\begin{array}{l}1 \\
2 \\
2 \\
2 \\
\end{array}$ & 2 & 1 & $\begin{array}{l}1 \\
1 \\
1\end{array}$ & $\begin{array}{l}2 \\
1 \\
1\end{array}$ \\
\hline
\end{tabular}

\section{Results}

Of the 25 patients $17\left(68^{\circ}{ }_{0}\right)$ showed a clinically significant antitumour response to the cyclical combination chemotherapy. In seven of these $17\left(28^{\circ}{ }_{\circ}\right.$ of all patients) measurable disease completely disappeared. The sites and duration of complete response are shown in table III. Lung, soft tissue, and lymph node lesions were the most responsive (table IV).

TABLE III-Site and Duration of Complete Remissions in 7 Patients

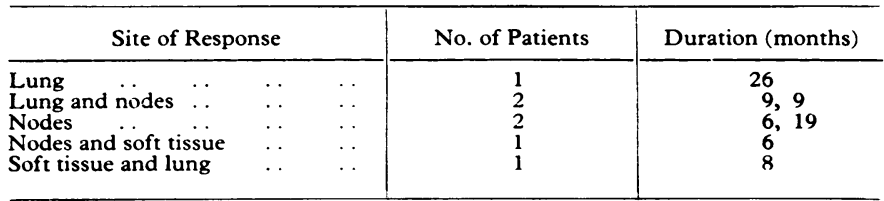

TABLE IV-Overall Response to Chemotherapy according to Metastatic Site

\begin{tabular}{|c|c|c|c|c|c|}
\hline \multirow{2}{*}{\multicolumn{2}{|c|}{ Organ }} & \multirow{2}{*}{$\begin{array}{c}\begin{array}{c}\text { No. } \\
\text { of } \\
\text { Patients }\end{array} \\
\end{array}$} & \multicolumn{3}{|c|}{ Response } \\
\hline & & & Complete & Partial & None \\
\hline $\begin{array}{lcc}\text { Nodes } & \ldots & \ldots \\
\text { Lung } & . & \\
\text { Skin and soft tissue } \\
\text { Liver } & \ldots & \ldots \\
\text { Bone } & \ldots & \ldots\end{array}$ & $\begin{array}{l}\cdots \\
\cdots \\
\cdots \\
\cdots\end{array}$ & $\begin{array}{r}7 \\
15 \\
8 \\
6 \\
13\end{array}$ & $\begin{array}{r}5 \\
6 \\
4 \\
-\end{array}$ & $\begin{array}{l}1 \\
1 \\
3 \\
3 \\
2\end{array}$ & $\begin{array}{r}1 \\
8 \\
1 \\
3 \\
11\end{array}$ \\
\hline
\end{tabular}

TABle v-Average Percentage of Optimal Dose per square metre of Body Surface Administered in each of first Six Cycles (Figures in Parentheses Represent Number of Patients)

\begin{tabular}{|c|c|c|c|c|c|c|c|}
\hline & & \multicolumn{6}{|c|}{ Cycle } \\
\hline & & 1 & 2 & 3 & 4 & 5 & 6 \\
\hline $\begin{array}{l}\text { Non-responders } \\
\text { Responders . . }\end{array}$ & $\begin{array}{l}\cdots \\
\cdots\end{array}$ & $\begin{array}{l}96(8) \\
97(17)\end{array}$ & $\begin{array}{l}93(7) \\
80(17)\end{array}$ & $\begin{array}{l}80 \text { (6) } \\
77 \text { (17) }\end{array}$ & $\begin{array}{l}80 \quad(6) \\
78 \text { (17) }\end{array}$ & $\begin{array}{l}83(3) \\
76(15)\end{array}$ & $\begin{array}{l}75 \text { (3) } \\
78(12)\end{array}$ \\
\hline
\end{tabular}

Bone lesions, though predominant in four patients, were also present in 11 others. A partial objective response of bone disease was noted in two patients and there was symptomatic benefit without radiographic healing. Relapse of the disease was usually accompanied by regrowth of tumour in previous areas of involvement. The survival curves plotted according to the life-table method (see chart) show that responders had a significantly

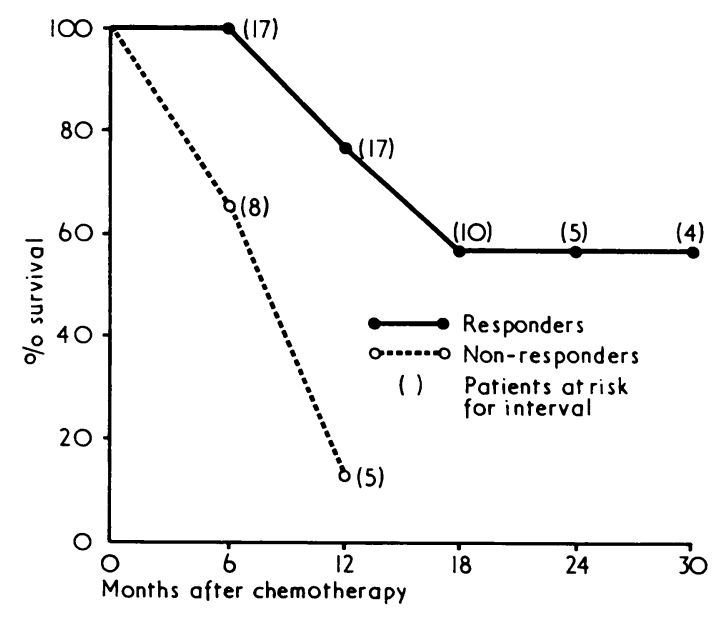

Life-table analysis of survival according to response.

greater survival than nonresponders. Seven of the eight nonresponders died, with a median survival time of six months, whereas the median in the 17 responders, out of whom 6 have already died, has not been reached but will be in excess of 13 months.

\section{TOXICITY}

The programme of intermittent chemotherapy was designed to allow gastrointestinal and haematological toxicity to recover between cycles. The toxicity of this regimen is tolerable, primarily haematological, and reversible. Mucositis was generally mild and did not limit the dose. Individual patient tolerance varied widely. Hepatic and marrow involvement were associated with the greatest degree of myelosuppression. There were no drug-related deaths, and 13 of the 17 responders received at least six cycles of treatment. The percentage of the optimal dose per square metre of body surface administered in each cycle is shown in table V. Some reduction in the average total dose was required for succeeding cycles of treatment. Only five patients developed a thrombocytopenia of less than $100,000 / \mathrm{mm}^{3}$ after the first two cycles, and each had bone or liver involvement. There was no difference between the responders and nonresponders. A moderate degree of alopecia was seen. No patient had haemorrhagic cystitis or corticosteroid-related side effects. The patients as a group received at least $75 \%$ of their calculated dose each monthly cycle.

\section{Discussion}

The results of this study suggest that multiple agent chemotherapy has a high response rate $(68 \%)$ in advanced breast cancer, especially in patients with visceral and soft tissue metastases. Furthermore, in seven out of 25 patients all metastatic disease disappeared, which is rare in the reported results with single agents (Eastern Co-operative Group in Solid Tumour Chemotherapy, 1967; Fracchia, et al., 1970; Nemoto and Dao, 1971; Sears et al., 1966). Most previously reported single agent series had only a $15-30 \%$ overall response rate. A variation in reported complete response rates might be expected in therapeutic trials according to the proportion of patients with metastatic bone disease. The extent of liver and bone involvement are more difficult to assess and thus less likely to be recorded as a response. Despite this, significant clinical improvement was seen when disease was primarily confined to these organs.

One patient showed radiographic bone healing, and in another severe hepatic failure, with bilirubin levels over $10 \mathrm{mg} / 100 \mathrm{ml}$, hypoalbuminaemia $(1.8 \mathrm{~g} / 100 \mathrm{ml})$, and a raised alkaline phosphatase $400 \mathrm{IU} / \mathrm{ml}$, was reversed. The median duration of anti- 
tumour response was nine months (range 6-26 months). The median duration of antitumour response is rarely reported, but, in one large co-operative group study of the antimetabolites, using 5-fluorouracil and methotrexate as single agents, the median duration of response was eight to 10 weeks (Eastern Co-operative Group in Solid Tumour Chemotherapy, 1967). Furthermore, the survival of the responders was only slightly better after six months of follow-up than the nonresponders with only $20 \%$ surviving at one year.

In most trials of combination chemotherapy the multiple agents were administered continuously (Cooper, 1969; Ansfield, et al., 1971). We thought that this approach, though effective, would result in a considerable reduction in dose, and to overcome this we used a cyclic or intermittent regimen. Vincristine was included in the earlier trials referred to above, but we did not give it because of possible severe neurotoxicity with prolonged administration and its low single-drug response rate.

Greenspan (1966) reported a $60 \%$ response rate with a combination of thiotepa and methotrexate without vincristine and $30 \%$ of his patients survived one year. Human breast cancer is a heterogenous disease, and it seems that our regimen is more effective in cases which metastasize rapidly. It uses rather high intravenous doses of the antimetabolites 5-fluorouracil and methotrexate. Tumours with a relatively high fraction of cells in the active cell cycle proliferation may reasonably be assumed to be likely to respond to this type of regimen.

The adjuvant administration of cytotoxic drugs after primary surgery with or without radiation therapy has shown some advantage in patients with a risk of developing metastatic disease (Nissen-Meyer et al., 1971). The rationale for this approach is that drug therapy might be more effective when the tumour cell mass in clinically undetectable. Our results in patients previously untreated with cytotoxic drugs suggest that combined chemotherapy is effective in reducing even large amounts of tumour with tolerable toxicity. If the subsequent pattern of metastatic disease can be predicted from clinical investigation of the biological characteristics of the primary tumour then our form of intensive combined therapy may be more effective for selected patients at risk of developing disseminated disease.

Requests for reprints should be sent to Dr. George P. Canellos.

\section{References}

Ansfield, F. J., Ramirez, G., Korbitz, B. C., and Davis, H. L. (1961). Cancer Chemotherapy Reports, 55, 183.

Ansfield, F. J., Ramirez, G., Mackman, S., Bryan, G. T., and Curreri, A. R. (1969). Cancer Research, 29, 1062.

Cooper, R. G. (1969). Proceedings of the American Association for Cancer Research, 10, 15 .

DeVita, V. T., and Schein, P. S. (1973). New England fournal of Medicine, 285, 998.

Eastern Co-operative Group in Solid Tumour Chemotherapy (1967). Fournal of the American Medical Association, 200, 770.

Fracchia, A. A., Farrow, J. H., Adam, Y. G., Monroy, J., and Knapper, W. H. (1970). Cancer, 26, 642.

Greenspan, E. Z. (1966). Fournal of the Mount Sinai Hospital, 33, 1

Nemoto, T., and Dao, T. L. (1971). New York State Fournal of Medicine, 71, 554 .'

Nissen-Meyer, R., Kjellgren, K., and Mansson, B. (1971). Cancer Chemo-

therapy Reports, 55, 561. Reports, 50, 271.

\title{
Reversible Encephalopathy Possibly Associated with Bismuth Subgallate Ingestion
}

\author{
RICHARD BURNS, D. W. THOMAS, V. J. BARRON
}

British Medical fournal, 1974, 1, 220-223

\section{Summary}

Four patients who had undergone abdominoperineal resection for carcinoma of the colon and who had been taking oral bismuth subgallate developed a stereotyped recurrent and reversible neurological syndrome. This was characterized by confusion, tremulousness, clumsiness, myoclonic jerks, and an inability to walk. All patients were extensively investigated and no cause could be found, but symptoms regressed when the intake of bismuth was stopped. Postmortem examination in one patient failed to show any appreciable abnormality apart from a loss of Purkinje cells in the cerebellum. In the other three patients amino-acid chromatography performed on urine showed the presence of an abnormal unidentified constituent. It is thought that these four patients developed an encephalopathy associated with their bismuth subgallate ingestion.

\footnotetext{
Department of Neurology, Royal Adelaide Hospital, and Institute of Medical and Veterinary Science, Adelaide, South Australia 5000 RICHARD BURNS, F.R.A.C.P., M.R.C.P., Visiting Neurologist

D. W. THOMAS, B.MED.SC., F.R.A.C.P., Assistant Director, Clinical Chemistry

V. J. BARRON, F.R.A.C.P., Physician
}

\section{Introduction}

Recurrent reversible confusional states lasting for several weeks are not common, especially in people who are apparently otherwise in good health. When caused by spontaneous hypoglycaemia the confusion is of shorter duration. Metabolic disturbances such as hyponatraemia or acute intermittent porphyria can be readily detected by appropriate biochemical tests, while the confusional states associated with failure of vital organs such as the heart, lungs, liver, and kidney are usually clinically obvious. There are other conditions in which an intermittent confusional state may be seen such as drug or alcohol intoxication, and sometimes even structural lesions of the brain such as an intermittent hydrocephalus. When there is a history of previous surgery for cancer then cerebral secondary deposits and the rare disorders of progressive multifocal leucoencephalopathy (Cavanagh et al., 1959) and limbic encephalitis (Corsellis et al., 1968) should also be considered, though these conditions usually have a progressive course.

We report on four patients who developed a very similar recurrent and reversible neurological syndrome consisting essentially of confusion, tremulousness, clumsiness, myoclonic jerks, and an inability to walk. In none of the patients were we able to identify any definable metabolic or structural disorder which could have been responsible.

\section{Case 1}

A 43-year-old farmer had an abdominoperineal resection for a carcinoma 